\title{
The Quality Management System of Additional Professional Education in Higher Educational Institution on the Basis of a Standard Quality System
}

\author{
Albert Simkin ${ }^{1}$, Tatyana Mozhaeva ${ }^{1,{ }^{*}}$ and Alexander Proskurin ${ }^{1}$ \\ ${ }^{1}$ Bryansk State Technical University, 7, 50 years of October st., Bryansk, 241035, Russia
}

\begin{abstract}
The strategic goal of the state policy of the Russian Federation concerning education is to ensure the quality of functioning of additional professional education (APE) as means of social development, and in this regard, the creation of a modern system of continuous education, i.e. the implementation of the concept of lifelong learning. The solution of this problem is possible on the basis of the development and integration into the overall management system of the educational organization of the quality management system (QMS) of additional professional education, taking into account the specifics of this type of activity. The paper is proposed to develop the QMS of APE of higher education on the basis of a standard model of quality system proposed in 2006 by a consortium of representatives of educational institutions of secondary vocational and higher education of the Russian Federation. The creation of quality systems of educational organizations on the basis of the model of QMS of OO considered in the article, adapted to the specifics of APE will contribute to the creation of conditions for ensuring the quality of training of students of professional educational programs.
\end{abstract}

\section{Introduction}

The implementation of the concept of lifelong learning, which is now a strategic priority of the state policy of the Russian Federation in the field of education, is carried out by means of the system of additional professional education (APE) as well. APE is considered as a purposeful continuous improvement of professional knowledge of citizens who already have professional education, updating their professional qualifications, preparation for the implementing new types of professional activities. The increasing APE role in the system of educational institutions is explained by the following reasons [1-7]:

- rapid deterioration of special professional knowledge of university graduates, due to the acceleration of scientific and technological progress, which results in their constant updating. Accordingly, changing the educational paradigm of the society "from education for life to education through life" becomes a necessary condition for professional growth;

\footnotetext{
*Corresponding author: goa-bgtu@mail.ru
} 
- imbalance between the needs of society and employers in competent professionals and the real level of professional training of University graduates;

- high labor mobility of the country population caused by dynamically changing economic conditions and requiring change of professional activity in short terms;

- great demand for professional educational programs, getting which allows you to obtain highly specialized knowledge quickly and acquire skills in a particular professional field.

APE is provided by a variety of organizations, in particular: educational organizations of secondary vocational and higher education (universities); APE institutions; specialized training centers, etc. Effective management of educational organizations for giving additional professional educational services provides for QMS integration into the general management system of the organization.

However, the study of this issue in practice showed that providing APE quality based on QMS development and implementation has not yet found proper application in the management of higher professional system, which is caused, in particular, by the peculiarities of additional educational services and a formal approach to them. In this regard, there is a need to understand the theoretical and methodological approaches to the development and improvement of QMS model in higher education institutions.

\section{Analysis of the state of the problem under study}

The analysis of scientific literature on this subject has shown that the following disadvantages are typical for QMS introduction into APE [8-16]:

- the activity of APE institutions is regulated by international standards (CQAF, ESG, ISO 9000, etc.), in connection with which QMS APE, developed and functioning on their basis, needs to be adapted to domestic realities (in particular, the limitation of bodies carrying out certification on the models under consideration);

- most of the existing QMS models in APE are an integral part of QMS of basic higher education without taking into account the features of this educational activity, in particular:

- the type of students (a great range of categories of students - undergraduate students of the University; graduates; heads of enterprises and organizations, etc.);

- APE regulating documentation (Federal laws of the Russian Federation; orders and guidelines of the Ministry of Science and Higher Education of the Russian Federation and of other departments; Federal State Educational Standards; including Occupational Standard concerning retraining or advanced training as a mandatory document of APE implementation);

- resource provision (flexibility, variety of resource use depending on the requirements of a specific professional educational program);

- the results of activities (established documents (certificate, diploma) in contrast to a state diploma while receiving basic higher education; improving the professional level of knowledge or acquiring new competencies (qualifications));

- monitoring of the process (APE evaluation is characterized by an integrative (complex) approach to the process, and the evaluation of learning outcomes is based on indicators that are important for the quality of professional activity), etc.;

- the top management of universities does not pay due attention to APE processes, considering them as secondary in the educational structure of the institution.

It should also be noted that the differences between Federal Educational Standards (FES) and Occupational Standards (OS) should be taken into account in the development and implementation of APE educational programs. All FES are based on the competence approach (the learning outcomes of higher educational programs are evaluated by the level of competencies formation), and OS - on labor functions. Coordination of FES and OS 
in the development and implementation of APE programs is possible on the basis of forming general requirements for knowledge, skills and abilities of specialists.

As the analysis of the publications mentioned above shows, in a situation when APE has become a social institution that helps to include a specialist in the sphere of fullfledged professional activity, increasing his competitiveness in the market economy, the procedure of QMS development, implementation and improvement is relevant and helps to avoid the identified shortcomings.

\section{Problem statement}

To eliminate the identified shortcomings in quality provision of APE the educational organization needs:

- to identify QMS model of additional professional education capable to guarantee effective control of educational process;

- to adapt QMS model to the processes of additional professional education taking into account the identified peculiarities.

In this regard, the use of typical QMS model considered in this paper is promising to solve this problem.

\section{Identification of QMS model of additional professional education}

Identification of QMS model, providing additional professional education, should take into account APE peculiarities and the possibility of integrating it into the overall management system of the organization. Currently, the models of quality systems based on the following standards are known and implemented in the world, including the Russian educational space: CQAF (Common Quality Assurance Framework); ESG - European Standards and Guidelines; ISO 9000 (ISO 9000 : 2015 "Quality management systems. Fundamentals and vocabulary", ISO 9001:2015 "Quality management systems. Requirements"); ISO $29990: 2010$ "Learning services for non-formal education and training. Basic requirements for service providers" etc. 


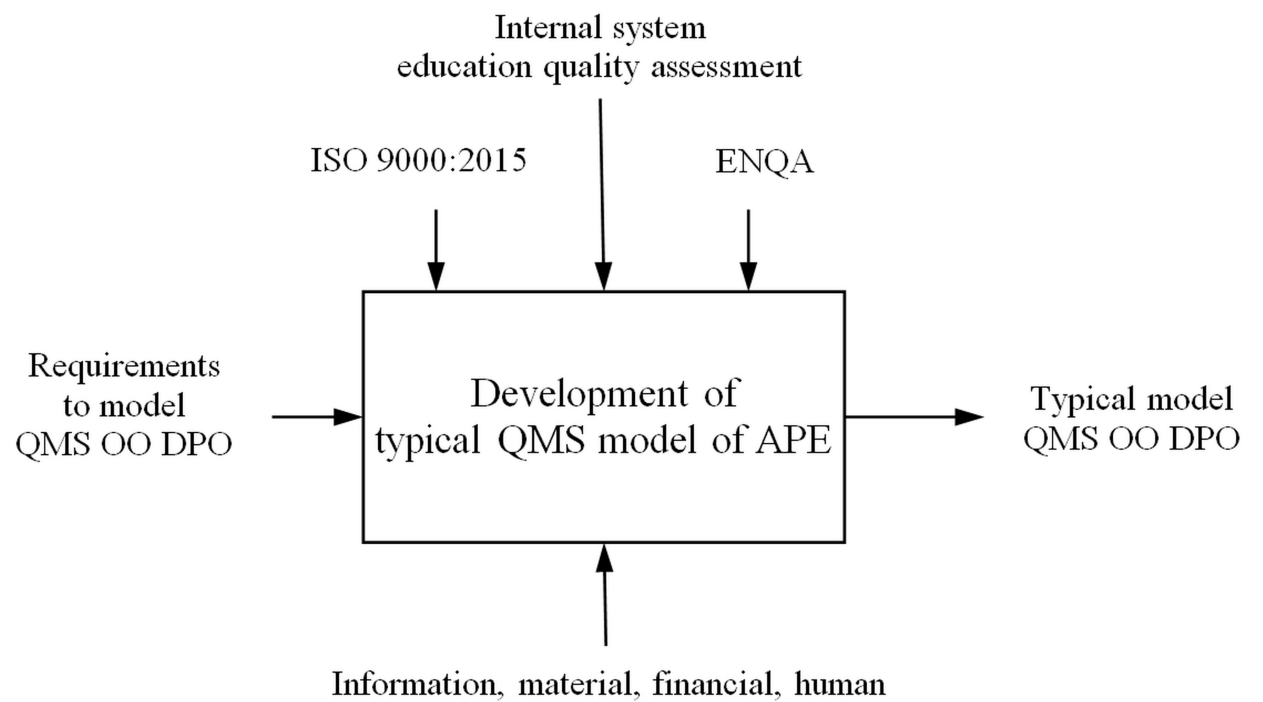

resources

Fig. 1. Information model of the process "Development of QMS model of APE".

However, the model of the quality system of the University should be easily integrated into the overall QMS of the educational organization. In this regard, it seems appropriate to use a model of quality system, proposed in 2006 by the association of representatives of 15 secondary and higher educational institutions of the Russian Federation (which included Bryansk State Technical University) [18].

The basis of QMS model is [19, 20] (Fig. 1):

- standards and guidelines for quality assurance of higher education in Europe (Standards and Guidelines for Quality Assurance in the European Higher Education Area) developed by the European Association for Quality Assurance in Higher Education (ENQA - European Network for Quality Assurance in Higher Education);

- ISO 9000 Quality Management Standards;

- internal system of education quality assessment.

Typical QMS model is adapted both taking into account the changes in its regulatory documentation (ENQA, ISO 9000, internal system of education quality assessment) and APE peculiarities.

\section{Conceptual provisions of the European standards and guidelines of quality assurance in higher educations}

European standards and guidelines for quality assurance of higher education are expressed in the following conceptual provisions that may be applied in APE [18].

1. Quality assurance policy. Educational organizations providing services in the field of APE should have a published policy that reflects their institutional vision and strategy. At the same time, employees and students of APE should develop and implement this policy with the involvement of employers and external partners.

2. Development and approval of programs. Educational institutions should have standards to develop and approve their professional educational programmes. Qualification, obtained in the result of the program, should be clearly defined, explained and must meet the requirements of educational and professional standards. Developing their programmes, 
educational institutions should ensure, inter alia, the participation of students in their development, as well as external evaluations of programmes.

3. Studentcentered training and performance evaluation. Educational organizations should implement studentcentered training processes in their programs. At the same time, the methods by which they are implemented should encourage students to play an active role in the joint formation of the educational process. In this regard, arrangement and use of elearning and distance learning technologies in the system of additional professional education are relevant.

4. Admission, academic performance, recognition and certification. Educational organizations should have predefined, published and consistently applied rules governing all periods of the student's life cycle, i.e. admission, academic performance, recognition and certification.

5. Teaching staff. Educational organizations should have objective and transparent processes for recruitment, professional growth and development of teachers that ensure and guarantee their competence.

6. Educational resources and student support system. Educational organizations should ensure the availability of sufficient, affordable and appropriate goals, curriculum resources and support services for students.

7. Information management. Educational organizations must ensure that they collect, analyse and use relevant information to manage their programmes and other activities effectively.

8. Public awareness. Educational organizations should publish information on their activities, including professional educational programs, which should be clear, accurate, objective, relevant and accessible.

9. Continuous monitoring and periodic evaluation of programmes. Educational organizations should conduct monitoring, periodic evaluation and continuous improvement of their professional educational programmes, in particular, with the involvement of students. Monitoring is aimed at ensuring that students and society are sure that professional educational programmes meet their needs.

10. Periodic external quality assurance procedures. Educational institutions should undergo external quality assurance procedures in accordance with European standards and recommendations on a regular basis.

The standards and guidelines for quality assurance in higher education in Europe (ENQA - European Network for Quality Assurance in Higher Education) are designed specifically for education. However, these standards do not provide recommendations to ensure the quality of education based on risk-oriented thinking, which is currently one of the conceptual features of the process approach to the management of the organization. In this regard, integration of GOST ISO $9000: 2015$ into the QMS of an educational organization providing additional professional educational services is a necessary and sufficient condition for its effective functioning.

\section{Methodological basis of GOST ISO 9000:2015}

With the approval of a new version of ISO $9000: 2015$ the standard model of the quality system should comply with new methodological provisions of these standards [19].

1. Context of the educational organization. An educational organization should identify external and internal factors that are significant in terms of its goals and strategic activities which affect the ability to achieve the expected result(s), as well as affect the approaches of the organization to the development and achievement of its goals. These factors may include positive and negative circumstances as well as conditions which are to be taken into account. 
2. Defining the scope of the quality system. The educational organization should define the boundaries and the field to apply the quality system in order to establish its scope. QMS scope should be framed and managed as documented information.

3. Quality system and its processes. The educational organization should establish, introduce, maintain and continuously improve the quality system, including the necessary processes and their interaction. In this regard, the organization should define the processes required for the quality system and their application in the organization.

Thus, process approach remains one of the main methodological principles to develop QMS of the educational organization, according to which the organization should provide not only a systematic definition and management of processes and their interactions in order to achieve the planned results in accordance with the quality policy and strategic directions of the development of APE, but also the management of processes and the system as a whole using the wellknown methodology "Plan-Do-Check-Act" (PDCA) focusing on thinking based on the assessment of risks and opportunities, as well as preventing unwanted results.

Activities and processes of QMS of APE are subjected to mandatory control. The standard QMS of APE provides for four levels of process maturity (Fig. 2) [14,15]:

- certainty (level I);

- reproducibility (level II);

- ability (level III);

- efficiency (level IV). 


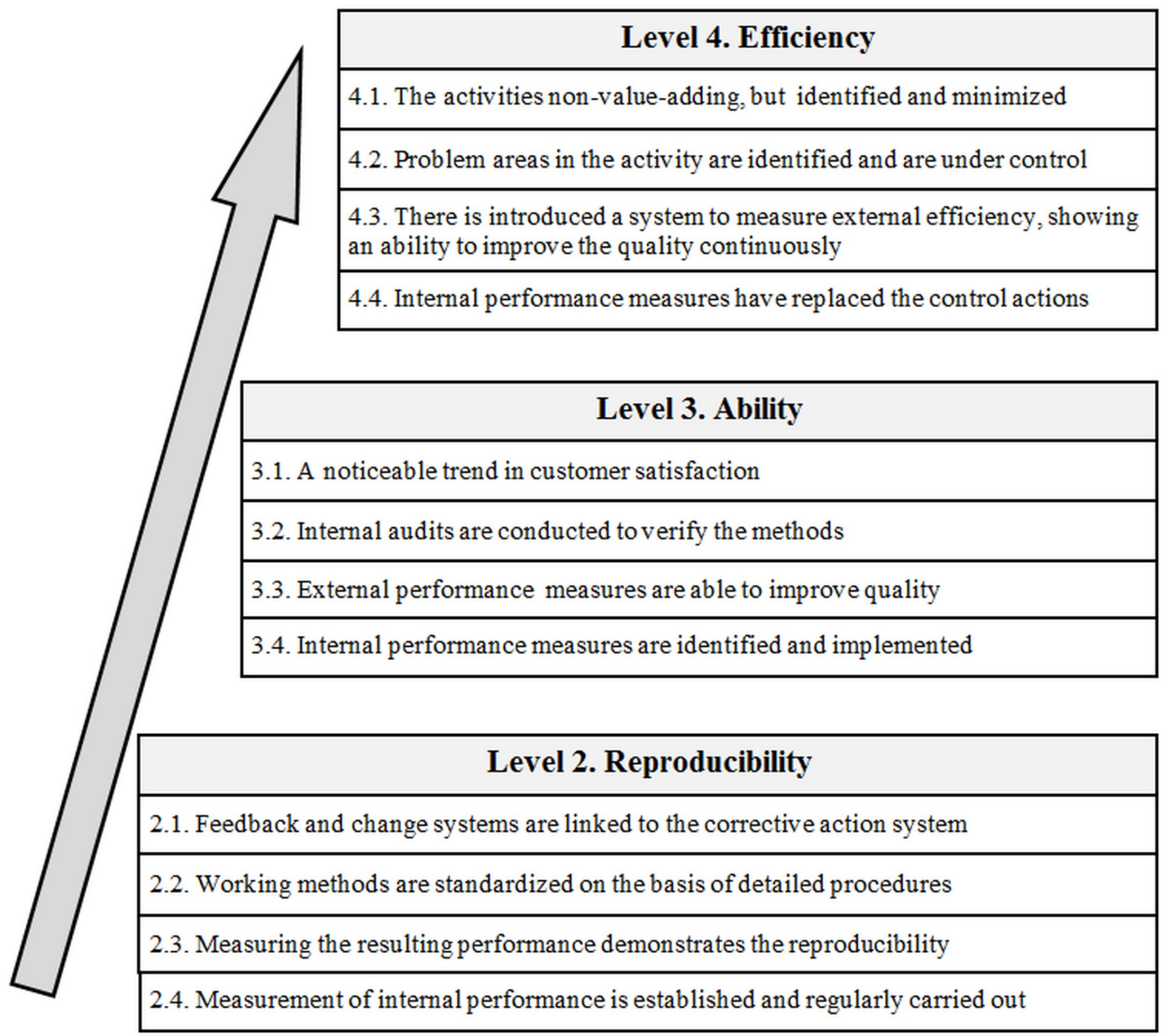

\begin{tabular}{|l|}
\hline \multicolumn{1}{|c|}{ Level 1. Certainty } \\
\hline 1.1. Consumers and their requirements are defined, there is a feedback system \\
\hline 1.2. Working methods are standardized on the basis of basic procedures \\
\hline 1.3. Consumer requirements are transformed into a performance criterion \\
\hline 1.4. The results are managed on the basis of after process control \\
\hline
\end{tabular}

Fig. 2. Maturity levels of QMS of APE.

4. Leadership. Top management and heads of other divisions of APE should show leadership and commitment to the quality management system.

5. Risk analysis in the quality system. The educational organization should provide for measures to address risks, as well as how these measures are integrated and implemented in the processes of the quality system; how to assess the effectiveness of these measures, whether they are adequate to the possible consequences of products and services discrepancy [20].

6. Analysis of using opportunities in the quality system. The staff of the organization should be trained in problem solving, finding and realizing opportunities for process improvement. At the same time, it is necessary to change the attitude to problems arising 
and consider their finding as new opportunities to improve the efficiency of the organization.

7. Knowledge base of educational organization. The educational organization should define the knowledge base necessary for functioning its processes and achieving products and services conformity. It should be kept uptodate and should be available for expansion when needed.

8. Documented information. The quality system of the educational organization should include documented information:

- required by ISO 9001:2015 standard;

- which the organization considers as necessary to ensure the effectiveness of its quality system.

\section{Internal quality evaluation system of additional professional education}

The given QMS of APE should be supplemented by an internal system of education quality assessment, the main function of which is to implement targeted and coordinated actions to organize and control in order to establish compliance of education quality with the requirements of the federal state educational standards, professional standards and (or) the needs of individual and (or) legal entities in whose interests educational activities are carried out, as well as in the implementation of preventive (assessment of risks and opportunities of educational organization) and corrective actions to improve the efficiency of educational processes in the educational organization [19].

The main objective of the internal system of APE quality assessment is to monitor the quality of education and identify areas of improvement in all activities of the educational organization and its departments.

The operation of the internal system of education quality assessment is carried out in the form of various control activities (inspections), which are determined by the decisions of the rector of the educational organization, vice-rectors and other officials in charge of APE, and is carried out through the following types of inspections: complex, planned, random and operational, as well as through selfinspection. Selfinspection is carried out by a department and is made in the form of reports for the calendar year.

The arrangement of procedures of APE quality assessment includes the following activities:

- development, approval and bringing to the attention of the participants of the educational process plans for quality control of APE;

- carrying out control actions with making a report;

- drawing up a plan of measures to eliminate the identified discrepancies;

- discussion of inspection results at meetings of departments and development of solutions to eliminate the identified discrepancies and to ensure the quality of education.

The criteria for assessing APE quality are:

- compliance of normative documentation and operational discipline with the requirements of licensing laws, professional and public accreditation of additional professional educational activities;

- determination of compliance of a professional educational program with the requirements of Federal State Educational Standard, Occupational Standard;

- determination of compliance of terms to develop the professional educational program, the quality of students' training, evaluation means of the organization, educational and methodical, financial and technical support of the professional educational program, staffing requirements of FES and OS;

- the quality of the final academic assessment of students and the demand for them; 
- students and employers' satisfaction with the training.

\section{Conclusion}

No doubt that the choice of a quality system model of APE should be made by the educational organization itself. However, the adaptation of a standard quality system model of the educational organization, successfully implemented for more than ten years in the system of higher and secondary vocational education of the Russian Federation, to the features of additional professional education will contribute to creating conditions to guarantee the quality of students' training and satisfaction of the society in providing the labor market with qualified specialists.

\section{References}

1. R.B. Barr, J. Tagg, Change 6, 13 (1995)

2. G. Becker, Human Capital: A Theoretical and Empirical Analysis, with Special Reference to Education (National Bureau of Economic Research, New York, 1964)

3. Education at a Glance 2017: OECD Indicators (OECD Publishing, Paris, 2017)

4. T. Hogan, An Overview of the Knowledge Economy, With a Focus on Arizona. Tempe: Carey School of Business (Arizona State University, 2011)

5. K. Robinson, L. Aronica, Creative Schools: The Grassroots Revolution That's Transforming Education (Viking, New York, 2015)

6. Y.R.C. Aymee, O.M.S. Alianis, V.F. Margarita, D.R. Rolando, T.B. Alberto, Contemporary problems of social work 2,114 (2018)

7. M.F. Rebelo, G. Santos, R. Silva, Journal of Cleaner Production 127, 96 (2016)

8. G. Panagiotou, Business Strategy Review, 14:2, 8 (2003)

9. C.J. Rees, E. Doran, The 6-th World Congress for Total Quality Management: Proceedings, 1, 485 (2001)

10. H.K. Rampersad, Total Quality Management: An Executive Guide to Continuous Improvement (Heidelberg, Berlin; Springer, New York, 2001)

11. T.L. Saaty, An eigenvalue allocation model for prioritization and planning (Energy Management and Policy Center, University of Pennsylvania, 1972)

12. E.C.Jr. Harrington, Industr. Quality Control , 21, 494 (1965)

13. European Assessor Training Modulus (Assessed version) (EFQM Publication, (2003)

14. E. Gossen, P. Kuske, E. Abele, Procedia CIRP, 28, 185 (2015)

15. G.M. Trishh, Eastern-European Journal of Enterprise Tehnologies, 4:3, 60 (2013)

16. D. Maletič, M. Maletič, B. Al-Najjar, B. Gomišček, IFAC Proceedings, 45:7 (2012)

17. O.A. Gorlenko, V.V. Miroshnikov, Typical quality system of the University: recommendations for implementation (BSTU, Bryansk, 2007)

18. V.I. Kruglov, Quarantee of education quality (TNT, Stary Oskol, 2017)

19. V.I. Kruglov, Quality of higher education (LETI, St Peterburg, 2018)

20. O.A. Gorlenko, N.M. Borbats, T.P. Mozhaeva, Vestnik bryanskogo gosudarstvennogo tekhnicheskogo universiteta, 1, 159 (2016) 